\title{
Post-pit optimization strategic alignment
}

\author{
by M.F. Breed* and D. van Heerden*
}

\section{Synopsis}

Successful development of projects or life-of-mine strategies requires an understanding of the relative sensitivity of value drivers such as grade, tonnage, energy costs, direct operational costs, and recoveries. For example, the results could vary significantly depending on the grade strategy, given a specific orebody amenable to open pitting.

Pit optimization is a very powerful tool widely used in the industry to determine the pit shell with the most attractive value potential. Based on the input parameters utilized, the pit optimization process determines the stripping ratio, mineable reserves, and pit shape, and effectively calculates a cut-off grade, assumed to be the optimal cut-off grade.

Once the initial pit optimization process is completed, the need may arise to align the optimization results with the company strategy by further optimizing other criteria, such as maximizing short-term cash flow.

This paper describes and discusses the selection of an alternative cutoff grade as a strategic intervention. It involves changing the cut-off grade, effectively increasing the head grade to gain a strategic advantage aligned with the company strategy, with a clear understanding of the financial value impact. With this knowledge, it is clear that pit optimization establishes the basis for future analysis and refinement.

Keywords

post-pit optimization, cut-off grade, optimal pit, ultimate pit, pit optimization. understanding the capacity constraints in the mine, mill, and the market. At any point during the life of mine, any or all of the limitations on tonnage mined, tonnage milled, and product sold may be constraining the system. To ensure cut-off optimization is done correctly, the capacity constraints must be independent of the cut-off grade.

This is to ensure an informed decision is made with regard to selecting an alternative cut-off grade as a strategic intervention to identify potential gain from the optimal pit shell, for future analysis and refinement.

This future analysis and refinement to achieve a strategic advantage could be based on optimizing other measures, such as annual cash flow, as defined in a company life-ofmine strategy.

\section{Pit optimization}

The first objective of a life-of-mine plan is to determine the maximum inventory of open-pit mineable reserves. Typically each block in the modelled resource will be assigned revenue and cost values. The algorithms developed by Lerchs-Grossman and others can then be used to determine the economic boundaries to the number of ore blocks that can optimally be recovered from open pit mining methods.

Newman et al. (2010) describe solving the final pit design, or the optimal pit shell, as a balancing act between stripping ratio and the cumulative value in the final pit limits. This analysis requires the cut-off grade to be fixed. Traditional open pit scheduling uses a resource model, assuming a fixed cut-off to determine a series of nested pits, in which a given price is used to define one pit and increasing prices

\footnotetext{
* Minxcon.

(C) The Southern African Institute of Mining and Metallurgy, 2016. ISSN 2225-6253. This paper was first presented at the, Mining Business Optimization Conference 2015, 11-12 March 2015, Mintek, Randburg.
} 


\section{Post-pit optimization strategic alignment}

correspond to larger pits. These pits are used to select the optimal pit. The typical design process is illustrated in Figure 1.

There are two principal methods to determine the shape of the optimal pit, namely the floating cone method (Laurich, 1990) and the method defined by Lerchs and Grossmann (1965). This method provides an exact and computationally tractable method for open pit optimization. Newman et al. (2010) indicate that Lerchs and Grossmann use a maximumweight closure algorithm that exploits network structure to produce an optimal solution. Many current commercially available software packages utilize this algorithm for pit optimization. The data for this paper was generated in one of these software packages, CAE NPV Scheduler.

Typical pit optimization input parameters include, but are not limited to, resource model, production rate, cut-off grade, operating and capital cost estimation, slope angles, treatment capacity, recoveries, and discount rate. The sensitivity of cutoff grade, taking cognisance of the other input parameters, should be considered to make informed decisions about the final parameters for the purpose of defining the life-of-mine strategy.

Experience shows that pit optimizations usually end upon selection of the ultimate pit, although there could be significantly more feasible or better strategically aligned options. Pit optimization only establishes the basis for future analysis and refinement as part of a post-pit optimization process.

\section{Defining a strategy}

Optimal grade cut-off selection is the foundation of the lifeof-mine strategy, being the driving force behind revenue generated. In addition to maximizing value, a life-of-mine strategy could be focused on other measures. Experience has shown that many strategic business decisions are based on measures of optimizing several other key performance indicators. These drivers of the strategy could include:

$>$ Annual cash flow

$>$ Life of mine

$>$ Operating risk

- Technical, economic. and political risks

> Product requirements (blending strategies).

Clarity on the strategy and understanding of the performance indicators are critical in order to complete a successful optimization process. Guided by the strategy and, importantly, understanding the value drivers, operational managers and corporate executives can confidently make decisions and select an ultimate pit. This pit shell will be used as the final pit limits for the life-of-mine schedule and will be the basis for a new optimal plan developed during a post-pit optimization process.

\section{Post-pit optimization process}

Once the final pit limits, based on sensible input parameters, have been selected, the iterative process to determine the optimal life-of-mine strategy can begin. The key to the process lies in understanding the fact that many of the decisions from one step impact all subsequent stages and that the entire process is a closed loop.

According to Hall (2009) a new optimal plan typically involves a significant increase in cut-off grade, especially in the earlier phases of the life of mine. This is typically associated with short-term increases in stripping ratios. Hall (2009) found that in many instances optimal plans are relatively insensitive to major changes of the value drivers, while sub-optimal plans have significantly higher financial risk when exposed to volatile markets.

Increasing the cut-off grade is not the only tool available to create a new optimal plan. Companies can also consider selecting a different pit, producing at a different rate, and developing stockpiling strategies.

It is clear that there are considerable benefits when operating within the limits of an optimal strategic plan that is continually driven by short-term strategic goals. The key to these short-term strategic decisions is an understanding of the longer term impact on the project value.

Unfortunately, experience has shown that decisions taken on achieving a short-term strategic advantage are often driven by operational managers trying to achieve production targets without understanding the longer term impact on overall project value. It is also true that some of these decisions arise from corporate influence, or even an industry that values only short-term performance while often failing to identify or just ignoring the long-term effects (Hall, 2009).

The process described in Figure 1 should be adapted to allow for post-pit optimization to achieve a strategic value gain within the ultimate pit.

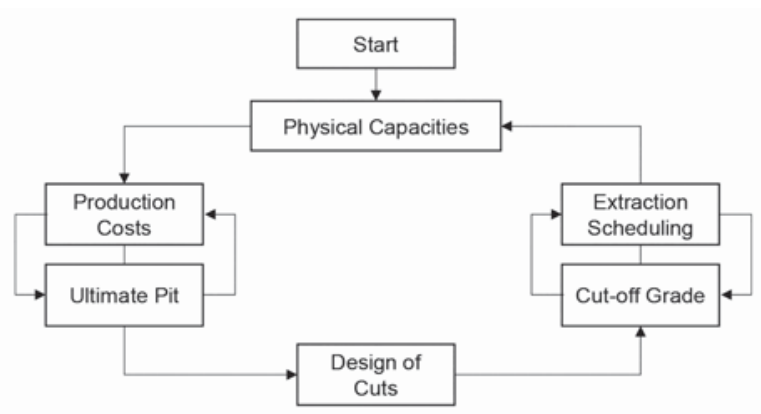

Figure 1-Steps of the traditional open pit mine design process (Dagdelen, 2001)

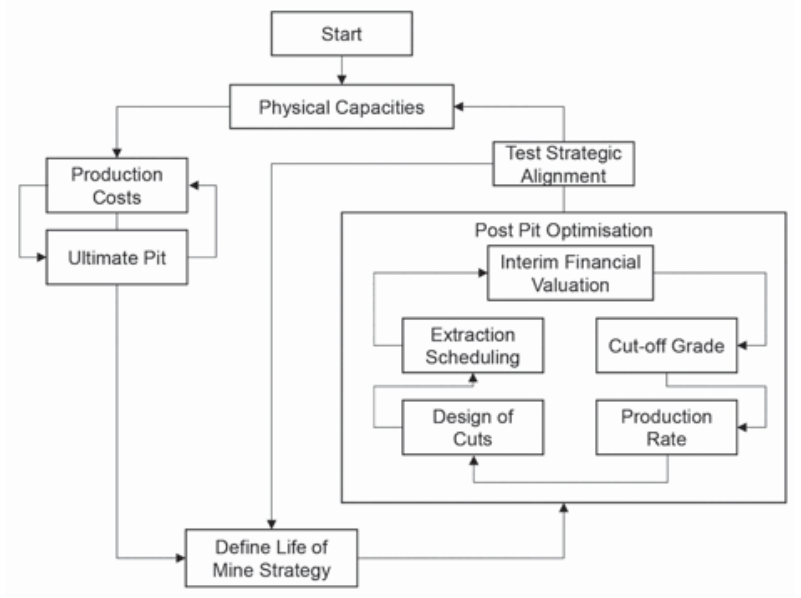

Figure 2-Post-pit optimization process 


\section{Post-pit optimization strategic alignment}

\section{Option selection}

Upon completion of a rigorous post-optimization process, operating managers and corporate executives can again confidently make decisions and select a life-of-mine option that achieves the measures defined for each key performance indicator, as defined in the company strategy. This decision is made with a good understanding of the relationship between short-term gain and long-term value. The decisions could result in one of the following scenarios:

1. Selection of a sub-optimal (with regard to value) pit shell with results closer aligned to the key performance indicators defined in the strategy

2. Re-evaluation of the input parameters to complete a new series of pit optimizations, to ensure that the selected pit is the optimal pit in terms of value and is also aligned to the key performance indicators.

It is important to understand that once this process is completed, the opportunity exists to review the strategy and initial ultimate pit selection. This could be updated or refined to gain a further advantage closing the process loop on the total pit optimization process.

\section{Case study}

To demonstrate the effect of changes to the input parameters during post-pit optimization, we will use a gold orebody as a case study. We will analyse the changes in value within the optimal pit limits of the pit optimization by updating post-pit optimization input parameters. This paper focuses on careful analysis of all the major value drivers to understand the long-term value impact.

\section{Optimal pit selection}

The economic pit limits define what can be economically extracted from a given orebody. To identify ore blocks to be mined the Lerchs and Grossmann (1965) algorithm is applied, based on assumed production and processing costs and commodity prices at current economic conditions.

At specific production rate and commodity price assumptions, the optimization software generates a graph indicating project value at specific progressive pit sizes. Figure 3 illustrates a typical graph with the values and other project indicators associated within the pits generated. Typically, the optimal pit selected will be the pit with the maximum value; however, the optimal pit for a specific scenario may be the one that maximizes the other performance indicators.

Figure 3 shows that all the pits can be economically extracted if capital is ignored. With all the information available, confident decisions can be made and sensitive areas, for example where the life of mine significantly reduces below Pit 12, can be avoided.

The optimization algorithm calculates a break-even cutoff grade without making provision for capital. This breakeven grade can be defined as an external cut-off - 'A cut-off applied during pit optimization, which controls whether a block is permitted to generate revenue. Blocks below this cutoff value are treated as waste, and the block's value is a negative one corresponding to the waste mining cost.' (Baird and Satchwell, 1999).
According to Baird and Satchwell (1999) the operation must be profitable to ensure a return on investment. One way of achieving this is to apply a break-even cut-off grade. Any credits will then be used to pay for the capital investment. Should the entire margin be used to pay capital during the payback period, the project might not yield an acceptable rate of return. This will then require selection of an alternative strategy to gain an advantage during the initial payback phase of the project, or a capital optimization study.

Selection of the final pit limits can be based on many measures. Typically the selection is done, but is not limited to, maximizing the key performance indicators as defined in the strategy.

\section{Defining a strategy}

The importance of a clearly defined strategy has already been highlighted. Just as important is a clear understanding of the value drivers, ensuring alignment to the key performance indicators. Ultimately, defining a strategy for post-pit optimization remains the determination of key performance indicators such as annual cash flow, life of mine, operating risk, technical, economic, and political risks, and product requirements.

As part of defining a strategy it must be decided where the focus of a post-pit optimization process will be. Post-pit optimization can be applied at various points in the pit design process, as illustrated in Figure 2.

The first opportunity for post-pit optimization is during the selection of the ultimate pit. This process has a loop where the selection of an economic pit should be aligned with the global performance indicators, as defined in the strategy. Figure 4 shows alternative pit options and the expected changes on two typical performance indicators when selecting an alternative pit.

The second opportunity arises once the economic pit has been selected. The post-pit optimization process proposed in Figure 2 can be followed to optimize the life-of-mine extraction strategy of the resource contained within the selected ultimate pit.

The theory and application of the optimization principles remain the same for both the post-pit optimization progressions.

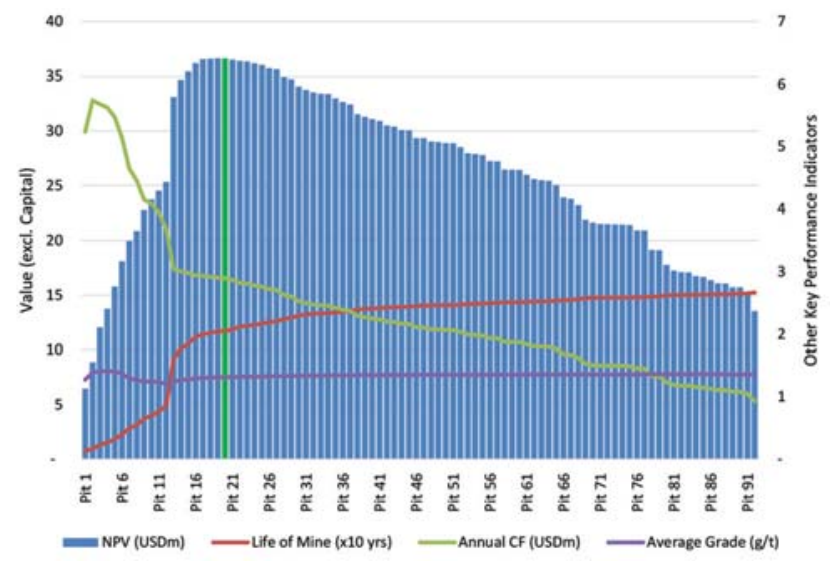

Figure 3-Pit optimization results 


\section{Post-pit optimization strategic alignment}

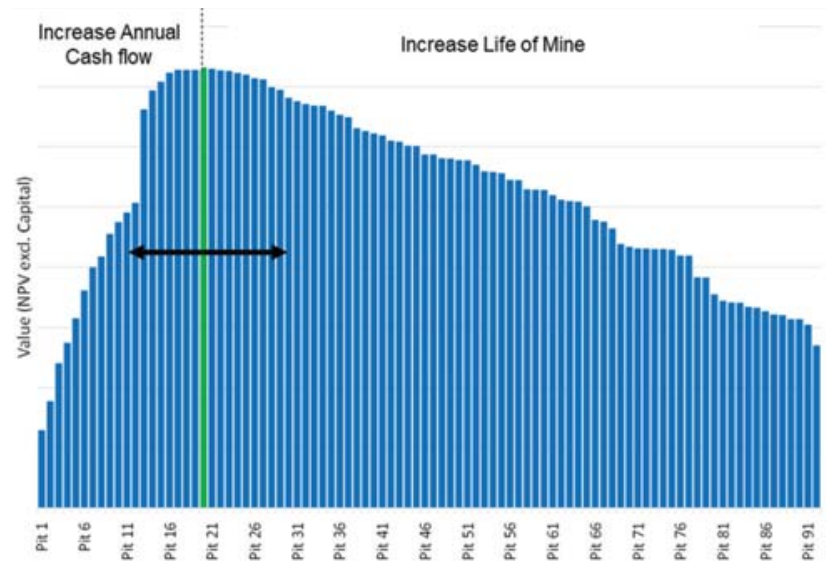

Figure 4-Selection of an ultimate pit

\section{Post-pit optimization}

In order to proceed with the case study it is necessary to define terms for the various pit shells referred to in this paper:

> Economic pit shell-defines what can be economically extracted from a given orebody

Optimal pit-typically the pit with the maximum value.

- Ultimate pit-selection of an alternative pit aligned with the defined strategy

> Final pit limits - pit shell selected for the final open pit mine design.

\section{Post-pit optimization - selection of ultimate pit}

Post-pit optimization for the selection of the ultimate pit involves an analysis of the data generated by the optimization algorithm to make a decision on the ultimate pit for the defined strategy. Figure 5 shows the optimal pit based on the maximum value. To align the pit selection with the strategy, we need to review the performance indicators. If the strategy is to increase the annual cash flow, for example to increase the rate of return, the pit selection will be a smaller pit. If the strategy is to increase the life of mine, for example to maximize the mineral reserves, a larger pit will be selected.

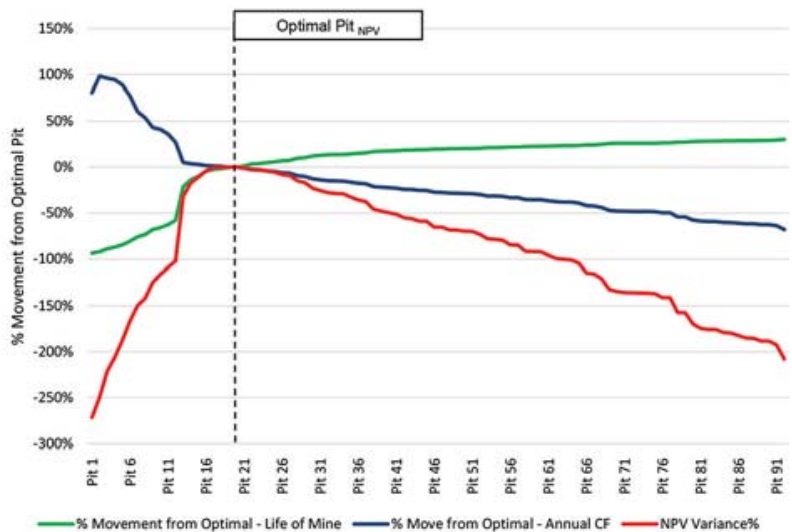

Figure 5-Life-of-mine and annual cash flow for different economic pits
With all the information available, operational managers and corporate executives can confidently make decisions and select an ultimate pit. If the strategy requires an ultimate pit within $20 \%$ of the optimal pit value, the selection would be limited to Pit 14 - Pit 29 (Figure 4).

\section{Post-pit optimization - optimize within ultimate pit}

Post-pit optimization within the ultimate pit will yield the same optimal value as for the ultimate pit selection.

Optimizing the life-of-mine strategy could involve variations on the internal cut-off grade and for production volumes within the ultimate pit; the changes in value are illustrated Figure 6.

The internal cut-off grade can be defined as 'a cut-off applied after pit optimization, to decide what to do with a block that falls inside the optimized pit and must be mined as either ore or waste' (Baird and Satchwell, 1999). The tonnage-grade curve representing the grade distribution within the ultimate pit shell will guide the process as it gives an initial indication of what changes can be expected to ore volume when varying the 'internal cut-off' grade.

The next step in the post-pit optimization process is to compare the optimal result with the company strategy by completing interim financial valuations. Figure 7 illustrates the possible variations of inputs to the optimal plan that could be considered to align the results with the company strategy. These changes may have a massive impact on the overall project value, as the strategy moves away from the optimal point. In addition the selected strategy may increase the operating risk.

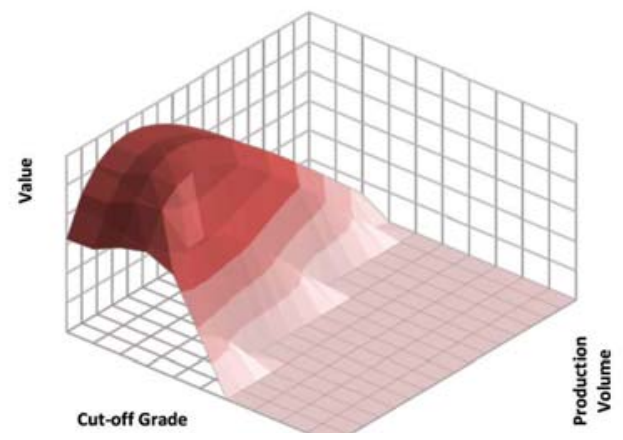

Figure 6-Value with varying cut-off grade and production volume

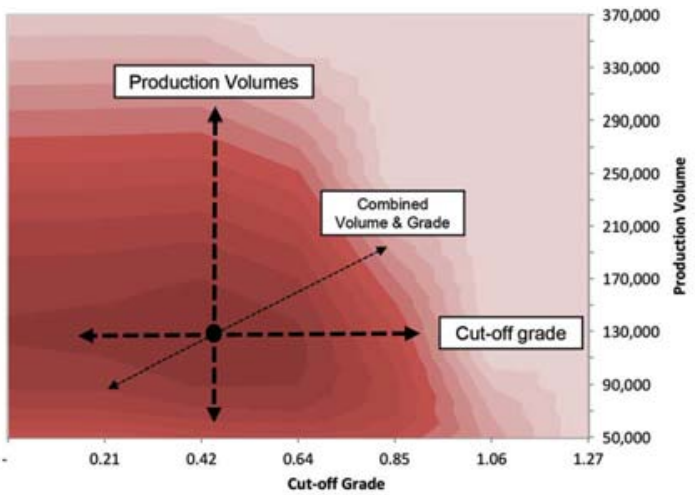

Figure 7-Variation of value from optimal point (contours of value increasing to optimal point) 


\section{Post-pit optimization strategic alignment}

Changes to the optimal pit production volume will always move the project to a sub-optimal option. This may be required in a market where commodity prices are constrained and product cannot be sold; a reduction in production volumes will then be required.

As the mining rate is increased, more material will be available for treatment, while increasing the cut-off grade will send higher grade material to the processing plant. The revenue will increase as a result of the higher grade and will more than pay for the increase in mining costs. As the production rate continues to increase, a point will be reached where the tonnage-grade relationship of the deposit will be such that any revenue gains will be exceeded by the mining costs, destroying value (Hall, 2009).

As discussed, developing a new optimal plan usually involves changing cut-off grade, which is always associated with production rate as a driver of the economic models. As examples, we will demonstrate two things companies could do to maximize life of mine and annual cash flow. At the optimal production rate, variations on the cut-off grade and the influence on the key performance drivers are illustrated in Figure 8.

From the graph it is clear that if the cut-off grade is decreased, there is a gain in life of mine. The important trade-off in this case is whether the loss of value compared to the increase in life of mine is acceptable for the company.

On the other hand, increasing the cut-off grade delivers higher grade to the processing plant, effectively increasing the annual cash flow. As expected, the continued increase in cut-off grade affects the tonnage-grade relationship to the extent that value is destroyed, resulting in a steep reduction of value. Again, the importance of the sensitive relationship between short-term gain and long-term value is highlighted as a significant project risk. If the strategy remains to select a cut-off grade scenario producing a value within $20 \%$ of the optimal pit value, the cut-off grade value would be limited to a maximum of $0.75 \mathrm{~g} / \mathrm{t}$

It is important to note that the analysis ignores the value of sub-grade material. According to Baird and Satchwell (1999), many company strategies plan to mine at an internal grade cut-off above the external 'break-even' cut-off grade, in order to assist the rate of return on investments. To achieve this, sub-grade material is stockpiled for treatment at some future date. However, for this to be feasible and practical the following criteria should be met:

- There must be space available for stockpiling material, and selective mining must be possible in the day-today operation of the project

> The stockpiled material must contain enough value to pay for additional re-handling and downstream processing costs.

A stockpiling strategy will influence the value line (NPV variance \%) in Figure 8 and should defer the downturn in value at a higher internal grade cut-off.

\section{Significance of discount rate}

Pit optimization determines the pit shell with the most attractive NPV. One of the factors that have a significant effect on the pit optimization process is the discount rate. The previous section describes the selection of optimal and ultimate pit, all based on the outcome defined by the project value.

\section{Sensitivity}

Determining a realistic discount rate for a project is one of the most difficult and important aspects of value analysis. The case study established that operational and corporate decisions on a discount rate, without due process, could lead to the selection of a sub-optimal pit. This could make or break a developing project. Figure 9 shows that at increased discount rates the pits selected contain less ore tons.

Further analyses of the optimal pits selected at the varying discount rates are illustrated in Figure 10. This clearly indicates that less ore tons are contained in the pits selected at higher discount rates. It is interesting to note, for this case study, that the grade does not decrease as the pit size increases. This is a function of much lower grades in the shallow oxide material being mined in the small pits. As the pit size increases the grade will increase as more of the deeper higher grade sulphide material can be extracted. This highlights the importance of understanding all the value drivers when evaluating projects.

To further illustrate the sensitivity of discount rate we analysed the four optimal pits generated at 0\%, 5\%, 10\%, and $15 \%$ discount rate. We selected each pit size and discounted the cash flow generated at various rates. Figure 11 illustrates the results and highlights the significance and sensitivity of using discount rate to select an ultimate pit. At $0 \%$ discount rate, the larger Pit 23 has the maximum NPV, and at the highest rate investigated, the smallest Pit 15 has the maximum NPV. It is important to understand that although there is only a maximum of

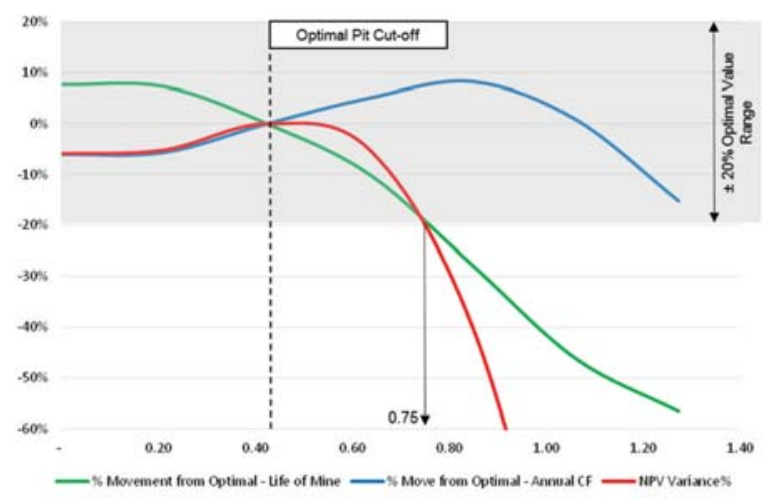

Figure 8-Life-of-mine and annual cash flow at varying cut-off grades

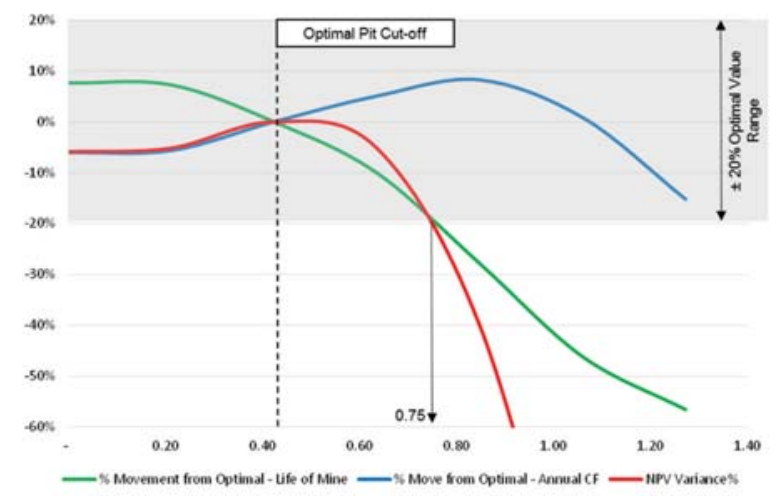

Figure 9-Pit optimization results - varying discount rate 


\section{Post-pit optimization strategic alignment}

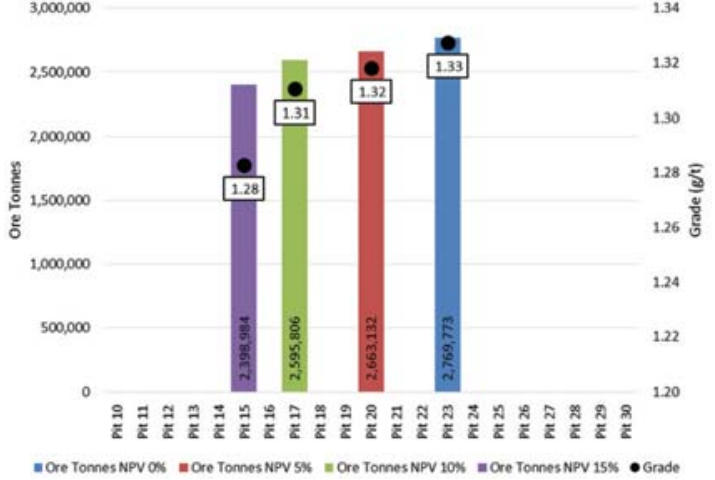

Figure 10-Discount rate analysis

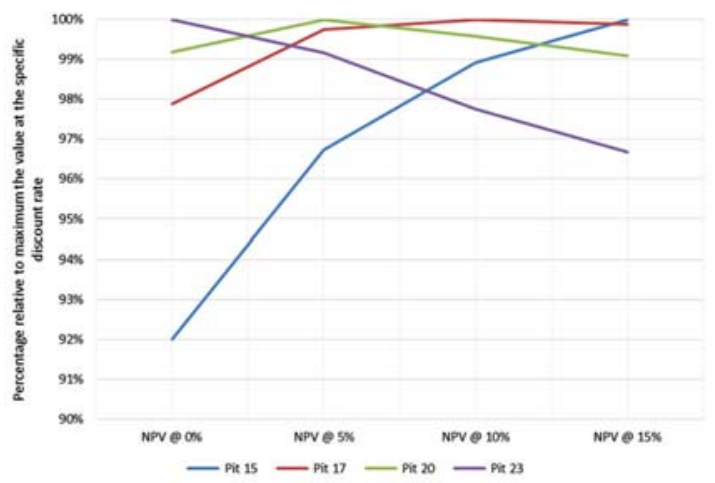

Figure 11-NPV variance with discount rate

$8 \%$ variance in NPV, the size of pit selected could significantly vary the mineral reserve. The difference in reserve ounces between Pit 15 and Pit 23 is 16\%.

\section{Selecting a discount rate for pit optimization}

Park and Matunhire (2011) stated that when evaluating mining investment opportunities, the risks associated with the mineral exploration and development should be considered. These risks are classified as technical, economic, and political risks. These risks are commonly accounted for by changing the discount rate to compensate for the variability of success.

During pit optimization, discount rate should not be applied to mitigate technical, economic, and political risk. The discount rate applied could be regarded as pure cost of capital. It is the rate of return a company must generate to compensate its investors. A risk-adjusted discount rate should be applied in the subsequent cash flow analysis. This rate can be calculated utilizing the capital asset pricing model and the weighted average cost of capital.

It is extremely important to understand the application of a discount rate in the software used for the pit optimization process. For example, the software may select an ultimate pit based on maximum cash flow, essentially a $0 \%$ discount rate. If an alternative discount rate is applied the software might not re-optimize, but just apply the adjusted discount rate to the ultimate pit's cash flow. The discount rate should be applied over the life of mine, discounting the value of the ore as the pit progresses, resulting in a smaller ultimate pit.
Determining a discount rate for pit optimization remains a difficult decision. However, the decision should be based on the key performance drivers defined in the strategy. Knowledge of the drivers and results obtained at varying discount rates, should assist in developing a strategically aligned life-of-mine strategy.

\section{Conclusions}

Traditional pit optimization provides an 'optimal' solution based on a fixed set of input parameters. Post-pit optimization is a process that requires analysis after the initial pit optimization. It may result in an ultimate pit that would be sub-optimal but which could be a better fit for the strategic goals of the company.

The project risk significantly increases if there is not an in-depth understanding of the effect changes to the optimization input parameters have on the overall project value. This includes operational and corporate decisions on a discount rate regularly made without due process.

The typical practice of selecting a cut-off grade, which is only one of the tools available to optimize a new plan, simply to increase grade trying to drive short-term revenue of a project, will often produce a sub-optimal life-of-mine strategy. This exposes the sensitive relationship between short-term gain and long-term value.

Understanding the changes and the economic drivers behind them will significantly reduce the risk of executing a sub-optimal life-of-mine plan. This effectively reduces the risk of not achieving the strategic advantage that a post-pit optimization process is intended to accomplish.

\section{References}

BAiRD, B.K. and SATChwell, P.C. 1999. Application of economic parameters and cutoffs during and after pit optimization. SME Annual Meeting, Denver, Colorado.

BAscetin, A. and NieTo, A. 2007. Determination of optimal cut-off grade policy to optimise NPV using a new approach with optimisation factor. Journal of the Southern African Institute of Mining and Metallurgy, vol. 107, no. 2. pp. 87-94.

DAGDELEN, K. 2001. Open pit optimization - strategies for improving economics of mining projects through mine planning. 17th International Mining Congress and Exhibition of Turkey. Chamber of Mining Engineers of Turkey. pp. 117-121.

HALL, B.E. 2009. Short-term gain for long-term pain - how focussing on tactical issues can destroy long-term value. Journal of the Southern African Institute of Mining and Metallurgy, vol. 109, no. 3. pp. 147-156.

LAURICH, R. 1990. Planning and design of surface mines. Surface Mining. Kennedy, B. (ed.). Chapter 5.2. Port City Press, Baltimore. pp. 465-469.

Lerchs, H. and Grossman, I.F. 1965. Optimum design of open-pit mines. CIM Bulletin, vol. 58, no. 633. pp. 47-54.

Newman, A.M., Rubio, E., Caro, R., Weintraub, A., and Eurek, K. 2010. A review of operations research in mine planning. Interfaces, vol. 40, no. 3 . pp. 222-245.

PARK, S-J. and MATUNHIRE, I.I. 2011. Investigation of factors influencing the determination of discount rate in the economic evaluation of mineral development projects. Journal of the Southern African Institute of Mining and Metallurgy, vol. 111, no. 11. pp. 773-779. 